\title{
Research on the Innovation Path to Strengthen Excellent Traditional Culture Education for Colleges and Universities in Shenzhen Under the Background of "Driven by Two Regions"
}

\author{
Jialiang Yang*, Peiheng Xu, Fenglian Li, Feng Ding \\ Shenzhen University, Shenzhen 518000, Guangdong Province, China \\ *Corresponding author: Jialiang Yang, yangj1@szu.edu.cn
}

Copyright: () 2022 Author(s). This is an open-access article distributed under the terms of the Creative Commons Attribution License (CC BY 4.0), permitting distribution and reproduction in any medium, provided the original work is cited.

\begin{abstract}
With a series of stated-issued policies to support the construction of the Guangdong-Hong Kong-Macao Greater Bay Area, Shenzhen has welcomed a major historical opportunity period of "driven by two regions." Shenzhen is a pilot demonstration area of socialism with Chinese characteristics and a dual core region of the Guangdong-Hong Kong-Macao Greater Bay Area. For colleges and universities in Shenzhen, this is both an opportunity and challenge. Under government support, colleges and universities in Shenzhen should carry out excellent traditional culture education, conduct top-level design, built an excellent traditional cultural education system, help students to form correct outlook on life and values, enhance a sense of national identity, supply first-class talents with both political integrity and professional competence for the two regions, as well as gather strength for developing the Guangdong-Hong Kong-Macao Greater Bay Area and pilot demonstration area of socialism with Chinese characteristics.
\end{abstract}

Keywords: Colleges and universities in Shenzhen; Driven by two regions; Excellent traditional Chinese culture; Innovation path

Online publication: January 20, 2022

\section{Introduction}

The excellent traditional Chinese culture is the historical accumulation of the development of the Chinese nation for 5,000 years. It is the spiritual home of the Chinese nation and contains rich ideology as well as cultural values. In August 2019, the State Council of the Communist Party of China commissioned Shenzhen as the pilot demonstration area of socialism with Chinese characteristics. Since then, Shenzhen, the core of Guangdong-Hong Kong-Macao, has a brand-new identity. The construction of "two regions" provides opportunity for the development in Shenzhen and sets higher demands. Shenzhen, as the core of "two regions," should play an exemplary role, focus on the construction of excellent traditional culture education, and provide momentum for long-term prosperity and stability of Guangdong, Hong Kong, and Macao. It is necessary to realize top-level design, play out the supporting role of the government, innovate excellent traditional culture education, maximize the education functions of excellent traditional culture, and promote education prosperity at the Guangdong-Hong Kong-Macao Greater Bay Area. 


\section{Contemporary values of excellent traditional culture in China}

The excellent traditional culture in China refers to the culture with rich and stable distinctive national features formed by the Chinese ethnic groups throughout the history of five thousand years. It is also the embodiment of politics, economy, system, and thought in the course of Chinese history. In order to cultivate high-quality talents, colleges and universities in Shenzhen should deeply explore the ideologies, humanist spirits, and moral principles in the excellent traditional Chinese culture, inherit innovation based on the requirements of the era, help the youth gain cultural confidence through the charm and the characteristics of the times shown by the Chinese culture, as well as patriotically carry out moral education. In order to promote education prosperity at the Guangdong-Hong Kong-Macao Greater Bay Area, it is necessary to persist in innovation of the times and values of the fine traditional Chinese culture.

\subsection{Excellent traditional culture helps contemporary youth to form cultural identity and gain cultural confidence}

Cultural identity refers to the cultural identity of a nation. Cultural identity should be built based on examining and understanding excellent traditional culture. Excellent traditional Chinese culture is extensive and profound; it contains rich ideologies, humanist spirits, and advances with the times ${ }^{[1]}$. Meanwhile, it is always filled with vigor as it absorbs healthy foreign culture in terms of spatial dimension and constantly realizes its development as well as growth.

\subsection{Excellent traditional culture promotes the principle of fostering character and civic virtue in colleges and universities}

Traditional Chinese culture with a history of 5,000 years contains rich thoughts on moral education and faces multicultural collisions. In the information age, there are various information; in the era of consumerism, personal values are shaken. Therefore, colleges and universities should remain true to the original aspiration, cultivate thoughts of moral education in the excellent traditional culture for contemporary youth, internalize and externalize the thoughts of moral education, help students to form correct outlook on life and values, as well as take up the role as a major site to strengthen moral education and cultivate people.

\section{The necessity to strengthen traditional culture education in colleges and universities in Shenzhen under the background of "two regions"}

At the current stage of development, it is imperative to transform Shenzhen into a law-based demonstration area, high-quality development area, urban civilization model area, a "happy" city, and a sustainable development area. As the strategic opportunity period of "two regions" is approaching, colleges and universities in Shenzhen should strengthen their excellent traditional culture education, which is not only a way to establish an urban civilization model, but also a strategy under the current pattern of the world.

\subsection{The new requirement for colleges and universities in Shenzhen is to strengthen traditional culture education under the background of "driven by two regions"}

Under the background of "driven by two regions," the construction of Guangdong-Hong Kong-Macao Greater Bay Area and the enhancement of core functions are the most important historical missions in Shenzhen in this new era. In establishing a new urban paradigm, Shenzhen should take the lead in strengthening cultural identity, promoting cultural confidence, and enhancing cohesion. Under the two policies - Guangdong-Hong Kong-Macao Greater Bay Area construction and the pilot demonstration area 
of socialism with Chinese characteristics, colleges and universities in Shenzhen should recall the original intention, take up the responsibility and mission of constructing the "two regions," as well as cultivate firstclass talents with both political integrity and professional competence for the construction of "two regions".

\subsection{The status of traditional culture education in colleges and universities in Shenzhen}

In the education system of colleges and universities, traditional culture education is still in the marginal status, with several weaknesses.

(1) Utilitarianism orientation

Traditional culture education is developing well in colleges and universities with good development trend. However, under the restrictions of evaluation rules in colleges and universities as well as huge employment pressure, most students still focus on scores and employment rates, thereby setting aside more time and energy in course learning for score acquiring and employment. In that case, the learning of traditional culture is superficial.

(2) Poor course development

With the rise of "classics learning," colleges and universities have introduced several courses that are relevant to traditional culture. However, efforts to develop courses in terms of the types and contents are insufficient. Therefore, it is necessary to strengthen the course development.

(3) Deviated focus

At present, traditional culture education in colleges and universities has some weaknesses, such as the tendency for sinologism and the emphasis on knowledge and inherence while neglecting practice and innovation.

\section{Innovation path of excellent traditional culture education for colleges and universities in Shenzhen under the background of "driven by two regions"}

Under the background of Guangdong-Hong Kong-Macao Greater Bay Area construction and the pilot demonstration area of socialism with Chinese characteristics, colleges and universities in Shenzhen are undertaking the mission of cultivating excellent talents for the "two regions". Under the background of "two regions," colleges and universities in Shenzhen should ponder about the innovation path for excellent traditional Chinese culture education, strengthen students' cultural identity, and establish cultural confidence.

\subsection{Realize top-level design and form a traditional culture education system in colleges and universities}

In order to strengthen traditional culture education in colleges and universities, it is necessary to carry out reasonable and scientific design planning. For a top-level design, it is necessary to carry out overall planning from many aspects. For system construction, it is necessary to obtain various expert demonstrations and put forward a traditional culture education system which meets the national requirements, social requirements, the requirements made by colleges and universities, as well as student development requirements ${ }^{[2]}$. Colleges and universities should propose policies relevant to classroom teaching, social practice, campus campaigns, and scientific research evaluation; they should also create an evaluation index for teachers and students as well as establish an incentive mechanism. Both, students and teachers, should be encouraged to participate in the education system by offering advice and suggestions to improve the system. It is necessary to ensure a top-level design for the traditional culture education system in colleges and universities, lead the organization design of teaching materials, guide the teaching methods of teachers 
and learning orientation of students, as well as lay a solid foundation for traditional culture education.

\subsection{Play the supporting role of the government, devise supporting policy documents, and guide colleges and universities to carry out traditional culture education}

Relevant sectors of the government should cooperate with colleges and universities, implement programmatic documents, carry out uniform deployment, investigate and carry out relevant measures, as well as provide funds for colleges and universities to carry out traditional culture education. Meanwhile, colleges and universities should call up people from organization departments at all levels, stimulate the enthusiasm of teachers and students to participate in traditional culture education, as well as carry through the work of traditional culture education.

\subsection{Learn from the experience and advanced methods of world-class colleges and universities}

It is necessary to carry out exchanges and discussions with world-class colleges and universities in terms of traditional culture education to learn from their experience and discuss on how to promote traditional culture education under their own existing system as well as to establish a scientific and reasonable traditional culture education system. In Singapore, the construction of its traditional culture education system is fruitful and flawless, which is worthy of reference and learning. Through state policy guidance, family education, and general education curriculum of traditional culture education in colleges and universities, the younger generation is deeply aware of the essence and connotation of traditional culture [3].

\section{Disclosure statement}

The authors declare that there is no conflict of interest.

\section{References}

[1] Wu X, (eds.) 2019, The Central Committee of the Communist Party of China and the State Council issued the "Outline for the Implementation of Patriotism Education in the New Era". People's Daily Online. http://www.gov.cn/xinwen/2019-11/12/content_5451352.htm

[2] Jin H, 2017, Strengthening Three Fields of Vision of Chinese Excellent Traditional Culture for Colleges and Universities - Times Values, Status Review, and Practice Path. Education Exploration, 2017(3): 83-85.

[3] Wang Y, 2019, Inspirations of Traditional Cultural Education in Singapore on Chinese Traditional Cultural Education in Colleges and Universities. Survey of Education, 2019(17): 18-20.

Publisher's note

Bio-Byword Scientific Publishing remains neutral with regard to jurisdictional claims in published maps and institutional affiliations. 